\title{
Simulation of a Heavy Rainfall Event on 14 September 2004 over Dhaka, Bangladesh Using MM5 Model
}

\author{
M. N. Ahasan ${ }^{1,2 *}$, M. A. M. Chowdhury' ${ }^{2}$ and D. A. Quadir ${ }^{3}$ \\ ${ }^{1}$ SAARC Meteorological Research Centre (SMRC), Dhaka, Bangladesh \\ ${ }^{2}$ Department of Physics, Jahangirnagar University, Savar, Dhaka, Bangladesh \\ ${ }^{3}$ Department of Physics, Uttara University, Dhaka, Bangladesh
}

Received 9 December 2010, Accepted in final revised form 5 April 2011

\begin{abstract}
An attempt has been made to simulate a heavy rainfall event on 14 September 2004 over Dhaka, Bangladesh using the fifth-generation PSU/NCAR Mesoscale model (MM5). This was an extraordinary rainfall event and recorded $341 \mathrm{~mm}$ rainfall in 24-h which was the highest ever recorded. The MM5 model was run on triple-nested domains at 45, 15, $5 \mathrm{~km}$ horizontal resolutions using Anthes-Kuo cumulus scheme. The model performance was evaluated by examining the different predicted parameters like mean sea level pressure, upper and lower level circulations, moisture, windshear, vorticity, convergence and rainfall. The model derived rainfall was compared with TRMM rainfall. The present results indicate that the MM5 model with the right combination of the nesting domain, horizontal resolution and cumulus scheme was able to simulate the heavy rainfall event, and associated dynamical and thermo-dynamical features reasonably well. The MM5 model suggested that the highly localized heavy rain over Dhaka was the result of an interaction of the monsoon land depression with southwest summer monsoon weather systems. The analysis shows that the depression almost remains stationary over southwest Bangladesh and zone of heavy rain was laid over Dhaka, and required moisture have been supplied from the Bay of Bengal.
\end{abstract}

Keywords: Depression; Heavy rainfall; TRMM; MM5 model; High resolution.

(C) 2011 JSR Publications. ISSN: 2070-0237 (Print); 2070-0245 (Online). All rights reserved.

doi:10.3329/jsr.v3i2.6656 J. Sci. Res. 3 (2), 261-270 (2011)

\section{Introduction}

On 14 September 2004, Dhaka $\left(23.77^{\circ} \mathrm{N}, 90.38^{\circ} \mathrm{E}\right)$ - the capital city of Bangladesh received unprecedented heavy rainfall and more than two-third of the city was inundated. This is an extraordinary rainfall event. The highest amount of rainfall in 24 hours was recorded at Dhaka (341mm), which were the highest ever recorded [1-2]. Due to these heavy rainfall flash flood situation was created in Dhaka and some parts of the country.

\footnotetext{
*Corresponding author: nazmul_smrc@yahoo.com
} 
Other nearby weather stations of Bangladesh Meteorological Department (BMD) recorded rainfall $376 \mathrm{~mm}$ at Maijdi Court, $422 \mathrm{~mm}$ at Sandwip, 234mm at Chandpur, $179 \mathrm{~mm}$ at Bhola, $170 \mathrm{~mm}$ at Comilla, $154 \mathrm{~mm}$ at Dhaka, $195 \mathrm{~mm}$ at Faridpur, $196 \mathrm{~mm}$ at Hatiya, $215 \mathrm{~mm}$ at Jessore and $184 \mathrm{~mm}$ at Tangail. This torrential rain disrupted life in the metropolitan capital city and caused flash flood situation. This extraordinary rainfall event occurred due to a land depression.

A low pressure area was formed over Northwest Bay and adjoining West Bengal coast on 10 September 2004. It intensified into a well marked low over the same area on 11 September 2004. On the morning of 12 September 2004 it concentrated into a land depression over southern part of West Bengal and adjoining Bangladesh. It moved north/northeasterly direction further inland and lay centred over Jessore, Faridpur and Pabna districts of Bangladesh as a land depression on 14 September 2004. The depression moved slightly northwards. Then again it moved southwestwards and weakened into a well marked low over Gangetic West Bengal adjoining Bangladesh. It moved westwards and weakened very slowly by giving heavy to very heavy falls [1, 2].

Heavy rainfall events become significant in human affairs when they are combined with other hydrological elements. The problem of forecasting heavy precipitation is especially difficult since it involves creating a quantitative precipitation forecast and is recognized as a challenging task [3]. Simulation of active mesoscale systems such as monsoon depressions and heavy rainfall episodes during monsoon season, with highresolution mesoscale models such as the fifth-generation PSU/NCAR mesoscale model (MM5), has been attempted by many researchers [4-7].

The objective of the present study is to simulate the heavy rainfall event which occurred over Dhaka on 14 September 2004 using high resolution (grid spacing of $5 \mathrm{~km}$ ) MM5 model, and to identify the possible synoptic condition and reason for such an event.

\section{Data Used, Model Experimental Setup and Methodology}

The fifth-generation PSU/NCAR mesoscale model version 3.7 [8] has been adopted for the mesoscale weather research and simulation at SAARC Meteorological Research Centre (SMRC), Dhaka, Bangladesh.

\subsection{Data used}

The NCEP high-resolution Global Final (FNL) Analysis data on $1.0^{\circ} \times 1.0^{\circ}$ grids covering the entire globe every 6-h were taken as the initial and lateral boundary condition. $30 \mathrm{sec}$ United States Geological Survey (USGS) data (Interpolated depending on resolution) GTOPO30 were used as Topography and 25 Categories United States Geological Survey (USGS) data were taken as vegetation / land use coverage. TRMM 3B42V6 daily data were used to compare or validate the model derived rainfall. 


\subsection{Model experimental setup and methodology}

The experiment was performed on triple-nested domains D1, D2 and D3 at 45, 15 and 5 $\mathrm{km}$ resolutions. The domain configuration in MM5 model for the present study is shown in Fig. 1. Domain 1 (D1) is the coarsest mesh and has $120 \times 105$ grid points in the north-south and east-west directions, respectively, with a horizontal grid spacing of $45 \mathrm{~km}$. Within Domain 1, Domain 2 (D2) is nested with $100 \times 94$ grid points at 15 $\mathrm{km}$ grid spacing. The fine-mesh Domain 3 (D3) is $151 \times 115$ points with $5 \mathrm{~km}$ grid spacing. The model uses two way nesting, where coarse grid data are interpolated to finer grid boundaries and the finer grid provides updated data to the coarse grid. All domains are centered $\left(20^{\circ} \mathrm{E}, 90^{\circ} \mathrm{N}\right)$ over Bangladesh to represent the regional-scale circulations and to solve the complex flows in this region. All these domains were configured to have the same vertical structure of 23 unequally spaced sigma (nondimensional pressure) levels. Bangladesh is the main focus point of this study. As such, the high resolution inner most domain (D3) is focused on Bangladesh only to observe the small spatial and temporal variability. The physical parameterization schemes used in this study are Anthes-Kuo (AK) for cumulus parameterization scheme, MRF for planetary boundary layer [9], Simple ice for an explicit moisture scheme [10], Simple cooling for radiation scheme and Five layer soil model for land surface processes.

The model was run for 36 hours based on the initial condition on 12 UTC of 13 September 2004. All parameters were made for 00 UTC of 14 September 2004 for the analysis of the synoptic conditions responsible for producing such heavy rain. The model performance was evaluated by examining the different predicted parameters like mean sea level pressure, upper and lower level circulations, horizontal and vertical profile of moisture and rainfall. The model derived rainfall was compared with TRMM. Surface simulated precipitation was considered as rainfall throughout the study.

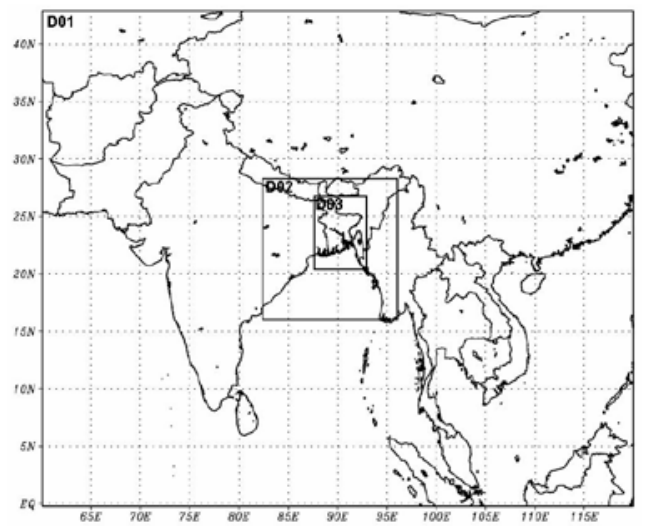

Fig. 1. Triple nested domains D1, D2 and D3 in MM5 model. 


\section{Results and Discussion}

\subsection{Mean sea level pressure analysis}

Summer monsoon rainfall over Bangladesh is characterized by significant wet (active) or dry (break) spells on a time scale of about two weeks [11]. The primary cause of these active and break spells are the fluctuations (i.e., intensity and position) of the seasonal monsoon trough. Monsoon trough is an extended trough of low pressure which runs across the Gangetic plains of north India with western end anchored to the seasonal heat low over northwest India and Pakistan, and eastern end emerging into the head Bay of Bengal. In the mean the axis of this trough runs from Ganganagar in Rajastan to Kolkata via Allahabad [11].

In addition to the heavy rain over Dhaka, the model also shows rainfall associated with large-scale processes such as seasonal monsoon trough. Model simulated mean sea level pressure (mb) for D1, valid for 00 UTC of 14 September 2004 is presented in Fig. 2. A prominent feature is the lowest surface pressure area lies over western part of Bangladesh and adjoining India. The heat low over Pakistan is very weak. The mean sea level pressure at the centre of the heat low is about $1005 \mathrm{mb}$ which is above normal (994mb) and the same over southern part of India is about $1011 \mathrm{mb}$ which made the weak north-south pressure gradient. The northerly positioned monsoon trough lies parallel to the foot hills of Himalayan mountain. The mean sea level pressure over Tibet is very high and central pressure was above 1035mb at 00UTC of 14 September 2004. The depression remains stationary over southwest Bangladesh and nearby Indian territory for long time may be due to this high pressure over Tibetan plateau and weak heat low.

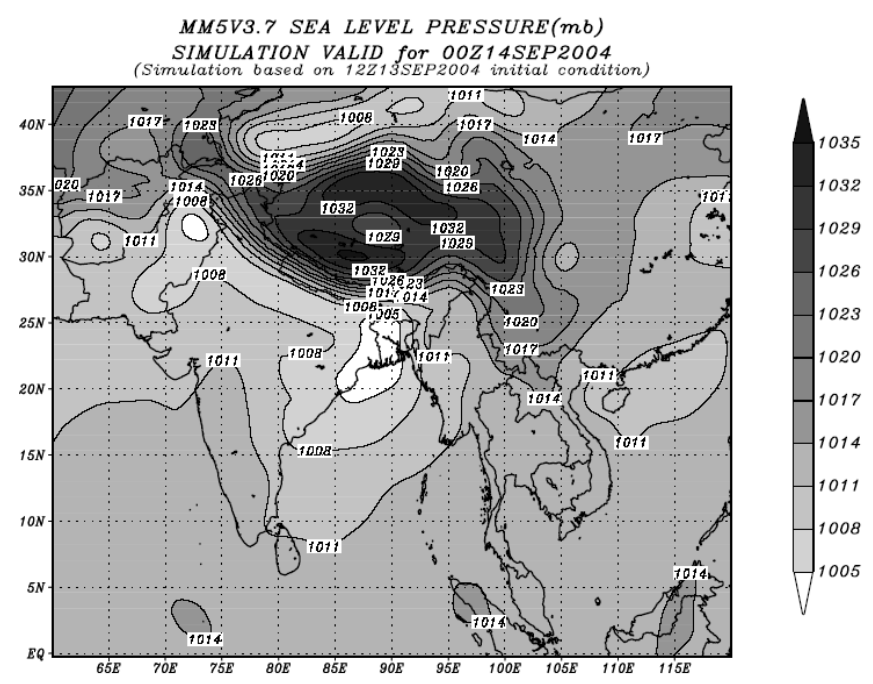

Fig. 2. Mean sea level pressure (mb) analysis, valid for 00 UTC of 14 September 2004. A prominent feature is the lowest surface pressure lies over western Bangladesh and adjoining territory of India. 


\subsection{Wind flow analysis}

One of the main synoptic conditions for occurrence of heavy rainfall over Bangladesh and neighbourhood is the southwesterly flow streaming from the head Bay of Bengal into Bangladesh during summer monsoon period [11]. The distributions of low level wind flow at $850 \mathrm{mb}$ and upper level wind flow at 500mb level valid for 00UTC, 14 September 2004 are presented in Fig. 3(a-b). The prominent feature is a strong southwesterly flow transporting high magnitude of moisture from the Bay of Bengal into southeast and central Bangladesh at 00UTC of 14 September 2004 [Fig. 3(a)]. The area of convergence (i.e., zone of high convective activity) observed over Dhaka and neighbourhood i.e., north-east sector of the depression. The southwesterly is prevailed over north Bay of Bengal and south Bangladesh up to $500 \mathrm{mb}$ [Fig. 3(b)]. A jet streak of about $20-30 \mathrm{~ms}^{-1}$ in the neighbourhood of Dhaka, Bangladesh is the prominent feature marking a strong vertical wind shear in the environment.
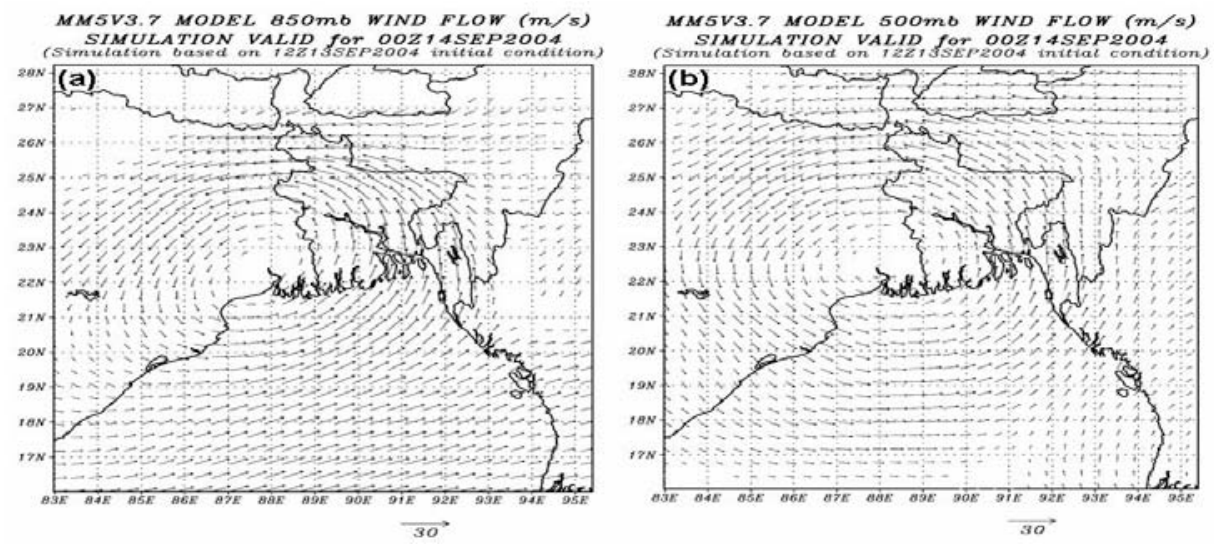

Fig. 3(a, b). Wind flow (m/s) analysis at (a) $850 \mathrm{mb}$ valid for 00UTC of 14 September 2004 and (b) $500 \mathrm{mb}$ valid for 00UTC of 14 September 2004. The prominent feature is strong southwesterly flow transporting moisture from the Bay of Bengal into Bangladesh [Fig. 3(a)].

\subsection{Vertical wind shear analysis}

Wind shear is very important factor for developing the convective systems. Vertical wind shear of the u component of wind $\left(\mathrm{ms}^{-1}\right)$ in the lowest $6 \mathrm{~km}$ of the atmosphere (500925mb), valid time 00UTC of 14 September 2004 is presented in Fig.4. It is found that the environment of Dhaka and neighbourhood was characterized by the strong vertical wind shear. A core of strong shear of the order of $12-15 \mathrm{~ms}^{-1}$ may be seen over central Bangladesh and neighbourhood is prominent. 


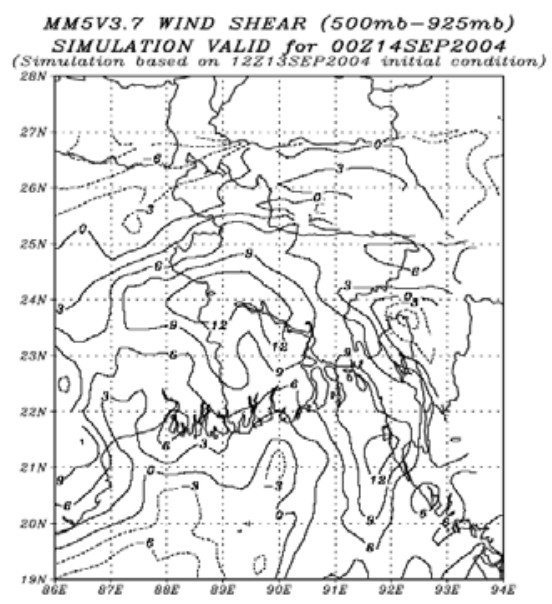

Fig. 4. Vertical wind shear of the u component of wind $\left(\mathrm{ms}^{-1}\right)$ in the lowest $6 \mathrm{~km}$ of the atmosphere (500-925mb), valid time 00UTC of 14 September 2004. A core of strong shear of the order of 12 $15 \mathrm{~ms}^{-1}$ may be seen in the central Bangladesh and neighbourhood.

\subsection{Low level relative vorticity analysis}

The MM5 model simulated low level relative vorticity $\left(\times 10^{-5} \mathrm{~s}^{-1}\right)$ at $925 \mathrm{mb}$, valid for 00UTC of 14 September 2004 are presented in Fig. 5. A prominent feature is an elongated vorticity maxima over central Bangladesh (north-west to south-east axis) and West Bengal due to horizontal shear in the southwesterly flow overhead the Bay of Bengal.

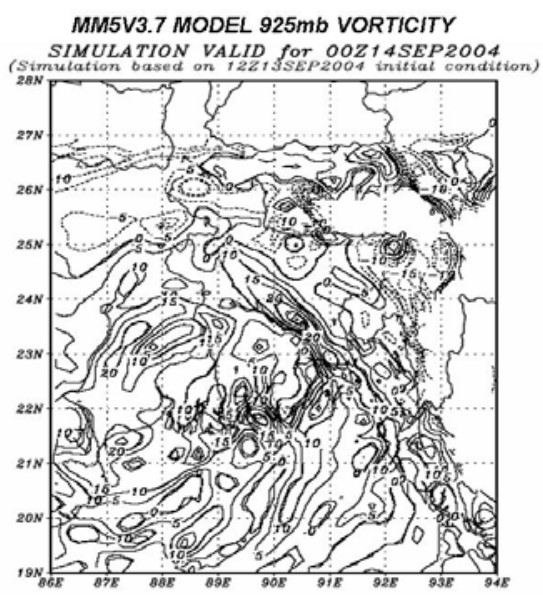

Fig. 5. Low level relative vorticity $\left(\times 10^{-5} \mathrm{~s}^{-1}\right)$ at $925 \mathrm{mb}$, valid for 00UTC of 14 September 2004. A prominent feature is an elongated vorticity maxima over central neighbourhood of Bangladesh and West Bengal of India due to horizontal shear in the southwesterly flow over head Bay of Bengal. 


\subsection{Low level divergence analysis}

Low level convergence is one of the important parameters to analysis the convection systems. The distribution of low level divergence at $925 \mathrm{mb}$ valid for 00 UTC of 14 September 2004 is shown in Fig. 6. A well defined area of low level convergence with maxima over central region of Bangladesh is clearly seen. The cutting across of the southerly low level winds and the convergence line/area over Dhaka is significant from the point of view of severe convective activity.

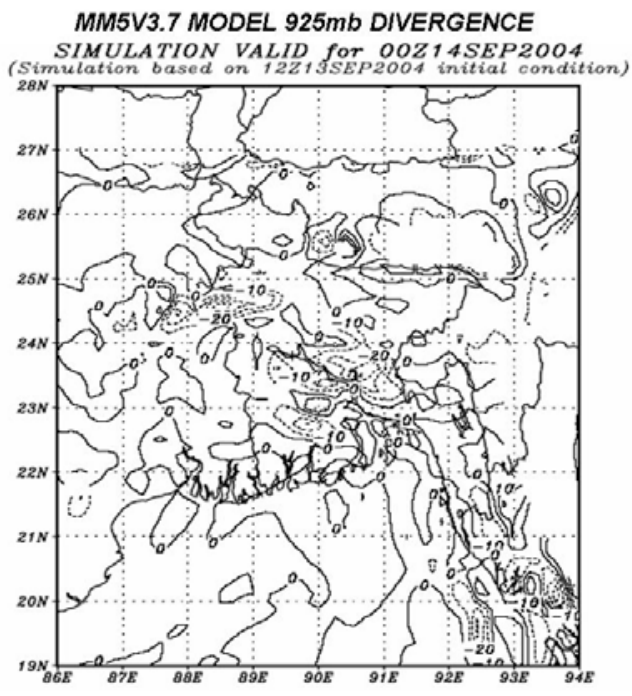

Fig. 6. Low level divergence (unit: $\times 10^{-5} \mathrm{~s}^{-1}$ ) at $925 \mathrm{mb}$, valid for 00 UTC of 14 September 2004. A convergence area may be seen over central region of Bangladesh and neighbourhood.

\subsection{High magnitude of humidity and its source}

The circulation of southwesterly flow transports plentiful of moisture from the Bay of Bengal to the plains of Bangladesh and neghbourhood. The spatial distribution of relative humidity at 00 UTC of 14 September 2004 is presented in Fig.7(a). It is found that the contents of high magnitude of moisture of the order of $90-100 \%$ over most of the region of Bangladesh at 00 UTC of 14 September, 2004. The vertical profile of relative humidity at 00 UTC of 14 September 2004 along the latitude of Dhaka $\left(23.77^{\circ} \mathrm{N}\right)$ is also presented in Fig.7 (b). It is found that the intensity of vertical profile of the relative humidity field reached up to $450 \mathrm{mb}$ just over Dhaka and it reached upto 200mb over some nearby places at 00UTC of 14 September 2004. Such type of vertical profile of relative humidity is hardly observed during summer season. 

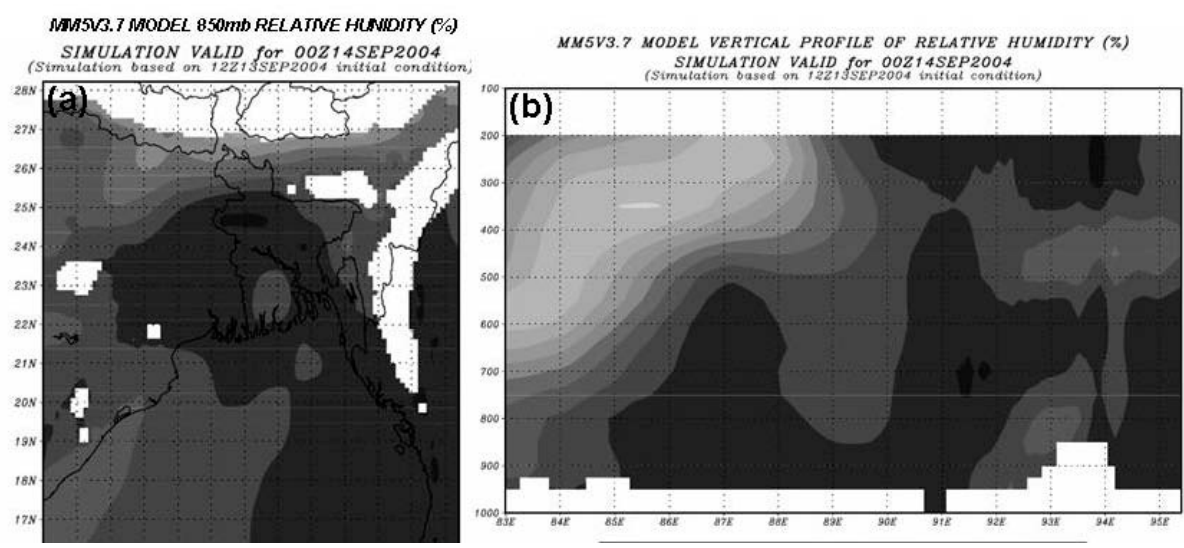

Fig. 7(a-b). Relative humidity analysis at 00 UTC of 14 September 2004 (a) and vertical profile of relative humidity at 00UTC of 14 September 2004 along the latitude of Dhaka $\left(23.77^{\circ} \mathrm{N}\right)$. The prominent features are the contents of high moisture of the order of $90-100 \%$ over Dhaka and neighbourhood.

\subsection{Rainfall analysis}

The MM5-model-simulated 24-h accumulated rainfall valid for 14 September 2004 for domain 3 (D3) at $5 \mathrm{~km}$ resolution is shown in Fig. 8(a). It is found that the high rainfall is

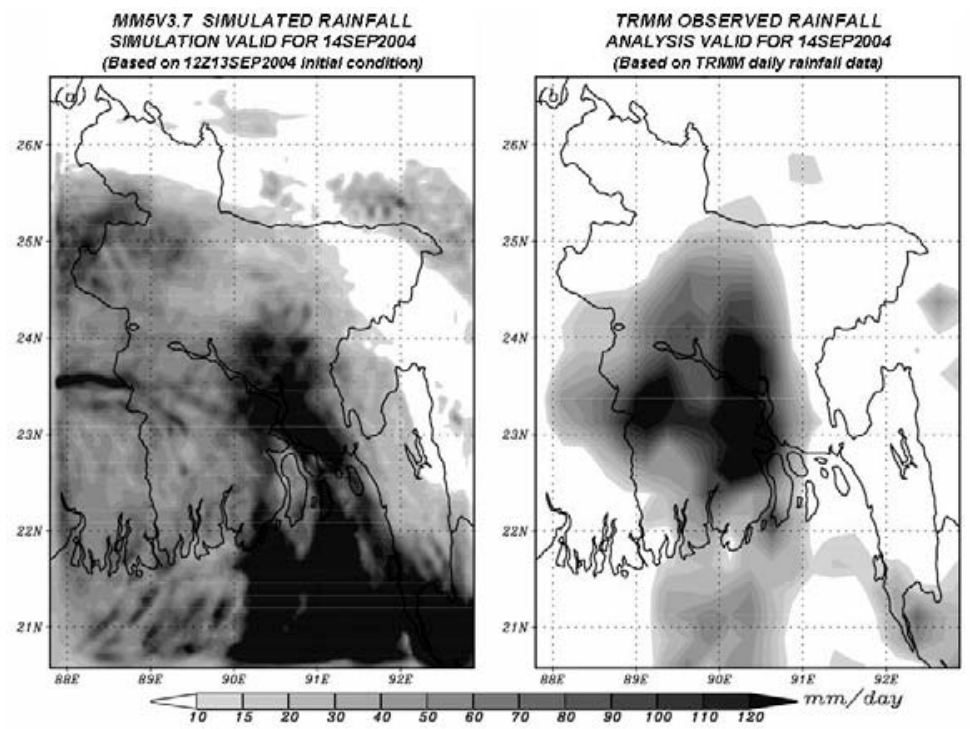

Fig. 8. Spatial distribution of model simulated 24-h accumulated rainfall (mm) valid for 14 September 2004 (a) and TRMM 3B42V6 observed rainfall (mm) valid for 14 September 2004 (b). 
seen in the vicinity of Dhaka. It also shows large spatial variability in north-south direction. The model simulated rainfall was compared with TRMM data [Fig. 8 (b)]. It is found that the model simulated rainfall using AK cumulus parameterization scheme with MRF PBL overestimated the TRMM. However, The MM5 model captured well the location and structure of the studied case. It seems that the intensity of the modelsimulated accumulated rainfall is higher than the same observed by TRMM. The TRMM underestimates the summer monsoon rainfall [12] in this region. Thus the MM5 model simulated rainfall seems to be realistic.

\section{Conclusions}

The simulation of a heavy rainfall event on 14 September 2004 over Dhaka, Bangladesh has been carried out using fifth-generation PSU/NCAR mesoscale model MM5.

On the basis of the present study, the following conclusions can be drawn:

(1) The MM5 model suggests that this heavy rain over Dhaka might be the result of an interaction between a monsoon land depression and southwest summer monsoon systems.

(2) The lowest sea level pressure was found over southwest Bangladesh and nearby territory of India. The land depression was not able to move further north due to the existence of intense high pressure cell over Tibetan plateau and further west due to very weak heat low over Pakistan.

(3) The analysis shows that the depression remains stationary over southwest Bangladesh and nearby territory of Indian on 14 September 2004 and the region of the high rain of the depression (i.e., convergence area) lies over Dhaka (i.e., north-east sector of depression), and required moisture has been supplied from the Bay of Bengal.

(4) The confluence of southwesterly flow transporting high magnitude of moisture from the Bay of Bengal towards central part of Bangladesh and neighbourhood.

Finally, we can conclude that the fifth-generation PSU/NCAR mesoscale model MM5 version 3.7 with the right combination of the nesting domain, horizontal resolution and cumulus parameterization schemes is able to simulate the heavy rainfall event over Dhaka, Bangladesh, and associated dynamical and thermo-dynamical features reasonably well.

\section{Acknowledgement}

The authors are grateful to anonymous reviewers for valuable and constructive comments, which helped to improve the manuscript. The authors are also grateful to Dr. Md. Nazrul Islam, Professor, Department of Meteorology, King Abdul Aziz University, K.S.A for helpful suggestions and encouragement. 


\section{References}

1. SMRC News Letter, SAARC Meteorological Research Centre (SMRC), 11 (2), 1 (JulyDecember 2004). http://www.saarc-smrc.org/nlJulDec04.pdf

2. http://en.wikipedia.org/wiki/Cloudburst

3. A. D. Charles, Scientific approaches for very short-range forecasting of severe convective storms in the United States of America, In: International Workshop on Observation/Forecasting of Meso-scale Weather and Technology of Reduction of Relevant Disasters (Tokyo, Japan, 1993) pp 181-188.

4. A. K. Bohra, Swati Basu, E. N. Rajagopal, G. R. Iyengar, M. Das Gupta, R. Ashrit, and B. Athiyaman, Current Science 90 (9), 1188 (2006).

5. A. J. Litta, B. Chakrapani and K. Mohankumar, Meteorol. Appl. 14, 291 (2004). doi:10.1002/met.31

6. S. Das, Mesoscale and cloud resolving scale simulation of a heavy precipitation episode and associated cloud system using MM5 model, INDO-US Workshop on Weather and Climate Modeling, New Delhi, India (2002).

7. R. K. Jenamani, S. C. Bhan, and S. R. Kalsi, Current Science 90, 1344 (2006).

8. G. A. Grell, J. Dudhia and D. R. Stauffer, A description of the 5th generation Penn State/NCAR Mesoscale model (MM5), NCAR technical note, NCAR/TN-398+STR (1994) p. 122.

9. S. Y. Hong and H. L. Pan, Monthly Weather Review 124, 2322 (1996). doi:10.1175/1520-0493(1996)124<2322:NBLVDI $>2.0 . C O ; 2$

10. J. Dudhia, Journal of Atmospheric Sciences 46, 3077 (1989). doi:10.1175/1520-0469(1989)046<3077:NSOCOD >2.0.CO;2

11. K. Prasad, Monsoon Forecasting using Numerical Weather prediction Guidance, SAARC Meteorological Research Centre (SMRC), Report No. 11 (2005).

12. M. N. Islam and H. Uyeda, Remote Sensing of Environment 108, 264 (2006).

$\underline{\text { doi:10.1016/j.rse.2006.11.011 }}$ 